\title{
Research on On-line Monitoring Methods of High Voltage Parameter in Electric Vehicles
}

\author{
Zhao chunming $^{1}$, Li qing ${ }^{2}$ \\ ${ }^{I}$ China Automotive Technology And Research Center, \\ No.218 Chenglin Road.Dongli District.Tianjin.300162 china \\ ${ }^{2}$ Tianjin Qingyuan Electric Vehicle Co.Ltd, \\ No.19, Xinye 5th Avenue, West Zone of TEDA, Tianjin, 300457, P.R.China \\ Email:zhaochunming@catarc.ac.cn.com \\ Email:lq@qyev.com
}

\begin{abstract}
Safety control and protection strategy of high-voltage system of electric vehicles include analysis of circuit condition before connection to high voltage terminal, transient current prevention for capacitive load, real-time monitoring and analysis of high-voltage system during operation, disconnecting strategy of high voltage terminals, vehicle dynamic safety and cooperative management of electrical systems, etc. Monitoring and analysis of some critical parameters of high voltage system such as insulation, electrical harness and connector condition are the basis and difficulties in high-voltage safety and protection. This paper presents several mathematical models of monitoring critical parameters, and experiments were also done to evaluate the model. Disadvantages of the commonly used calculation method are discussed. Single point insulation defect model is introduced and diagnosis method of multiple points defect is also discussed. To satisfy high voltage safety management system based on micro-controller, online diagnosis method of related parameters is studied. Hardware-in-loop (HIL) and complete vehicle experiment were conducted to prove the validity, response and reliability of the proposed method.

Keywords-high-voltage system, On-line monitoring methods,electric vehicles
\end{abstract}

\section{Introduction}

The main characteristics of high voltage system in an electric vehicle are high voltage and high current.

Electric vehicles with similar performance as conventional vehicles have higher voltage than safety voltage and the impedance of the electrical system is small. Normal operation current of such high voltage system can reach up to hundreds of amperes while the short circuit current can be several times higher than normal current. As a result, safety of the vehicle and passengers should be considered carefully when designing the high voltage system. Studies on failure mode, self diagnosis, invalidation strategy and safety control strategy are thus critical. Monitoring and analysis of main parameters in high voltage system including insulation condition, connection condition of electrical system and high voltage connector condition as one of the difficulties in safety control and protection strategy, is studied in this paper.

\section{Safety parameters of high voltage system and monitoring}

\subsection{Resistance between high voltage system and vehicle body}

Insulation level between high voltage system and vehicle body is a critical criteria in determining safety of an electric vehicle. If at some point the insulation condition degrades, electric shock may happen.

Mature method on measuring and analyzing insulation condition of high voltage battery system using embedded system has not been reported. [3] proposed a calculation method on insulation resistance of battery pack, however some of its assumptions are not right. For example, it assumes insulation weakness always happens at either anode or cathode which is too simplified. It also assumes " $V_{1}+V_{2}=V_{b}$ " which cannot be demonstrated at good insulation condition because effective circuit is not 
even formed. This standard can be improved in either theory or practicability.

\subsection{Modeling of single-point insulation}

\section{weakness of battery pack}

Most insulation weakness occurs at certain point in high voltage system. If the mathematical model of single-point insulation weakness can be obtained, weakness point can be than characterized. Fig. 1 shows a single point insulation weakness. Assume an insulation weakness occurs at some point in battery pack and has a resistance to ground of Ri. Its voltage is lower than anode by $\mathrm{U}$. When a volt meter with internal resistance of R0 is used to measure anode voltage to ground, V1 is obtained. The portion of the battery that has voltage $\mathrm{U}$, $\mathrm{R} 0$ and Ri form current loop 1 . When a voltmeter with same internal resistance R0 is connected to cathode, V2 is obtained and the portion of the battery that has voltage $\mathrm{Vb}-\mathrm{U}, \mathrm{Ri}$ and R0 form current loop 2.

From loop 1 and loop 2, following equations can be obtained,

$$
\begin{aligned}
& \frac{U}{R_{0}+R_{i}}=\frac{V_{1}}{R_{0}} \\
& \frac{V_{b}-U}{R_{0}+R_{i}}=\frac{V_{2}}{R_{0}}
\end{aligned}
$$

With (1) and (2), not only insulation resistance of high voltage system can be obtained, but also the insulation weakness can be located by (3a) and ( $3 b)$

$$
\begin{aligned}
& R_{i}=\frac{R_{0}}{V_{1}+V_{2}}\left(V_{b}-V_{1}-V_{2}\right) \\
& U=\frac{V_{1}}{V_{1}+V_{2}} V_{b}
\end{aligned}
$$

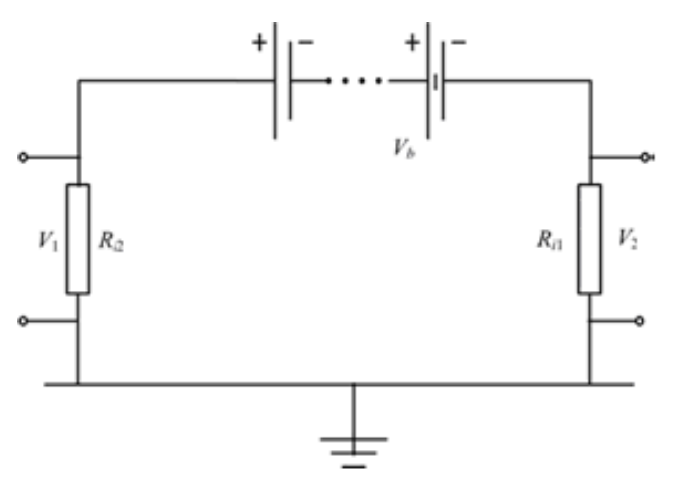

Figure1: Principle map of single-point insulation weakness

\subsection{Determination of multi-point insulation}

\section{weakness}

Single-point insulation weakness is one of the phenomenons of insulation degradation. If insulation weakness happens at more than one point, the model proposed in previous section cannot represent actual insulation condition of high voltage system. In this case, accurate modeling is difficult and no publications have been reported yet.

The author proposed a "Floated ground balancing method using double current loop double internal resistance". This method, as shown in Fig.2, tells the severity of insulation weakness.

\subsection{Connection condition of propultion}

\section{electrical system}

There are two methods to monitor connection condition of electrical system for propulsion. One is auxiliary low voltage circuit method and the other is dynamic electrical parameter method. The first one needs additional low voltage circuit and the advantage is accurate measurement on contact resistance of certain part of the circuit, however high voltage circuit or failure may cause safety problems.

The second method dynamically variance of contact resistance of the circuit of which voltage and current are measured. It simplifies a high voltage system to the configuration shown in Fig. 3. The battery is considered to be a constant voltage source $\mathrm{E}$ and internal resistance of $\mathrm{Ri}$ in series, $\mathrm{R}$ is the sum of wiring resistance and contact resistance, so we have $\mathrm{R}+\mathrm{Ri}=(\mathrm{E}-\mathrm{V}) / \mathrm{I}$. If one point is taken to be base point which has current of I1 and voltage of $\mathrm{V} 1$, measurement at any point with current I 2 and voltage V 2 can be used to calculate instantaneous contact resistance by equation, $R+R_{i}=\left(V_{1}-V_{2}\right) /\left(I_{1}-I_{2}\right)$. This method has benefits of reducing the influence to high voltage circuit, comprehensive monitoring including contact point and battery internal resistance, however the polar resistance of the battery various with different SOC, ambient temperature and current which may generate error in calculating contact resistance using dynamic parameters.

\subsection{Condition of high voltage contact}

To enable the control function of the whole vehicle and automatic disconnection to protect high voltage circuit, a connector that can automatically disconnect power circuit should be used in an electric vehicle. If necessary, some electric vehicles even need more than two of such components. In the case that high voltage contact fails and no proper action can be taken in time, normal control function will not be effective and even worse accident may happen. As a result, effective real-time monitor of high voltage contact is critical to safety and reliability of an electric vehicle. 
There are two methods to monitor contact or relay, one is to monitor (current in its coil?) the other is to measure the contact or relay itself. The first method is simple but it is indirect representation of the object being measured. The second method is straightforward but relatively difficult to realize. Fig. 4 shows the diagram for high

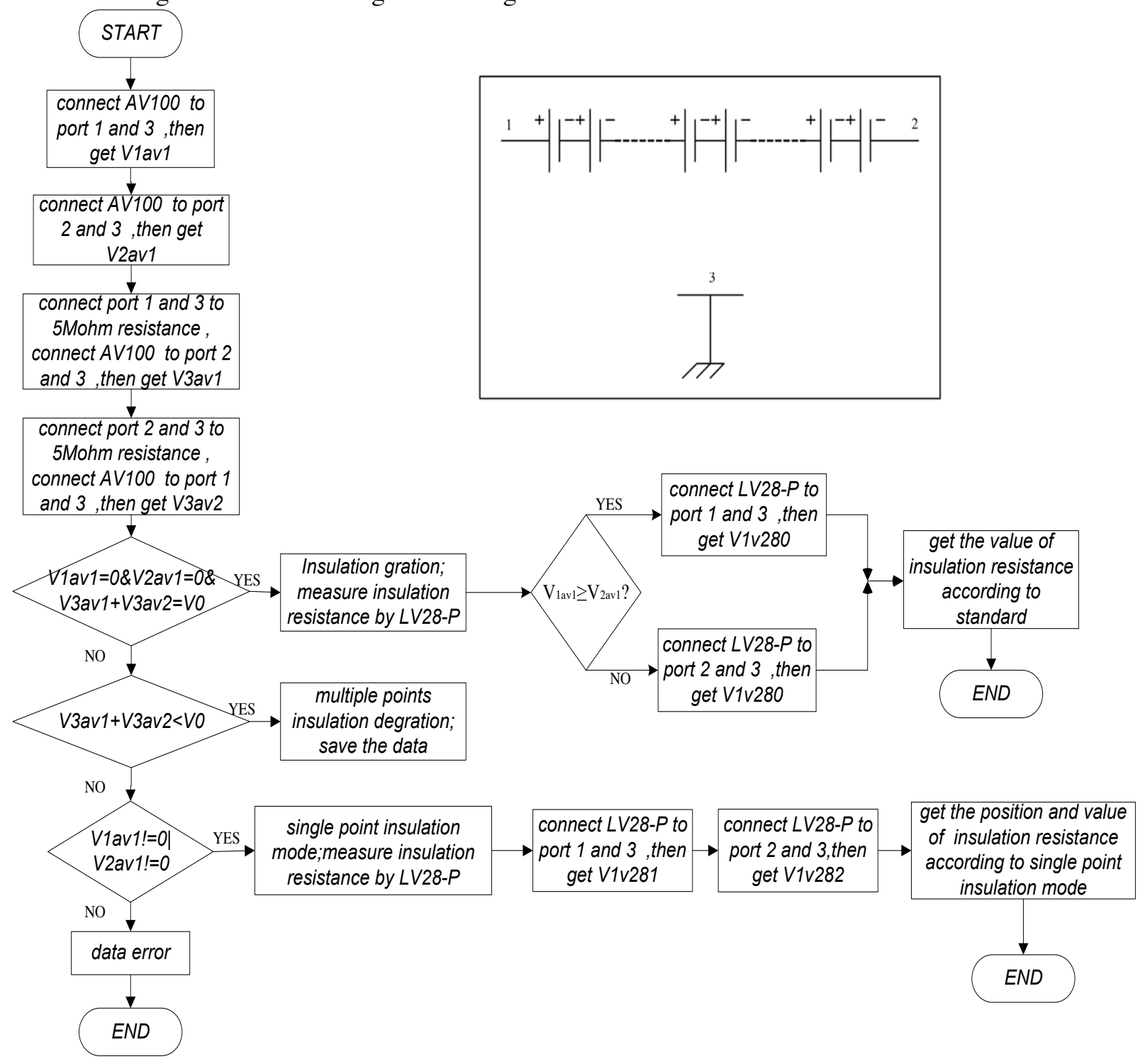

Figure2: Flow chart of insulation situation analysis
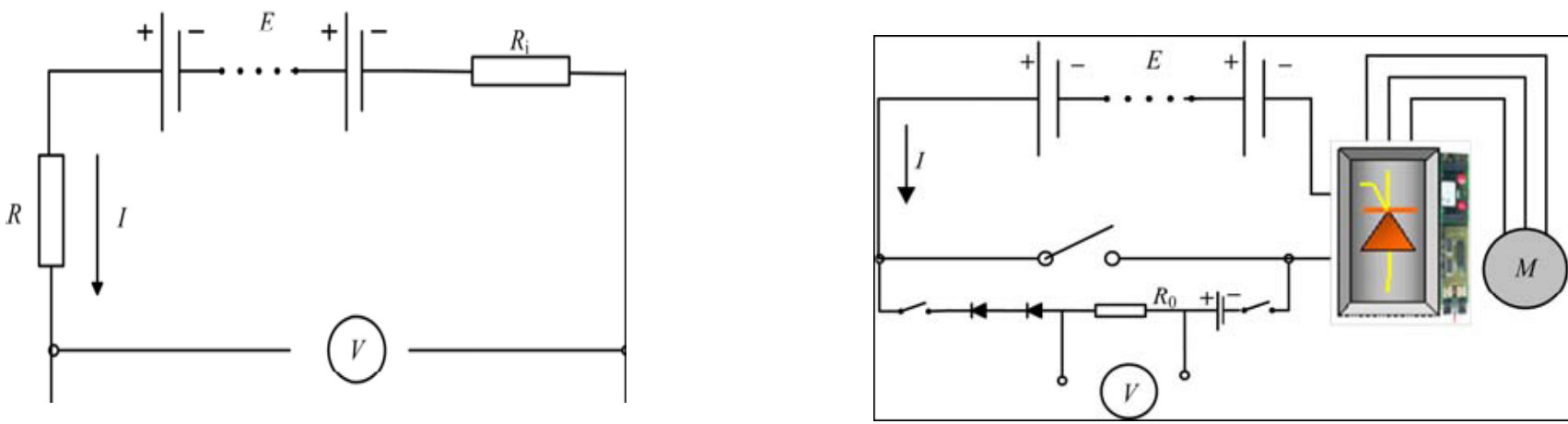

Figure3: Simplified electro circuit model of high-voltage system voltage contact monitoring. Voltage $\mathrm{V}$ can directly represent the status of high voltage contact. 


\section{Experiment validation and analysis}

\subsection{Insulation resistance}

We connected various points in battery pack to the chassis with $50 \mathrm{k} \mathrm{ohm}$ resistors and validate the inspection method for single point insulation weakness. The experiment result is shown in Tab. 1.

Table1: Validation test of single-point insulation weakness

\begin{tabular}{|c|c|c|c|c|}
\hline $\begin{array}{l}\text { vehicle } \\
\text { state }\end{array}$ & part & $\begin{array}{c}\text { voltage } \\
\text { of "+" to } \\
\text { bodywork } \\
\mathrm{V}\end{array}$ & $\begin{array}{c}\text { voltage } \\
\text { of "-"” to } \\
\text { bodywork } \\
\mathrm{V}\end{array}$ & result \\
\hline \multirow{3}{*}{$\begin{array}{c}\text { master } \\
\text { contactor } \\
\text { switch-off }\end{array}$} & total'+' & 120.12 & 1.81 & $\begin{array}{l}\mathrm{R}=52.3 \mathrm{k} \Omega \\
\mathrm{U}=281.3 \mathrm{~V}\end{array}$ \\
\hline & total'-' & 0 & 123.24 & $\begin{array}{c}\mathrm{R}=51.3 \mathrm{k} \Omega \\
\mathrm{U}=0 \mathrm{~V}\end{array}$ \\
\hline & grouped & 56.16 & 63.96 & $\begin{array}{l}\mathrm{R}=53.7 \mathrm{k} \Omega \\
\mathrm{U}=133.5 \mathrm{~V}\end{array}$ \\
\hline \multirow{3}{*}{$\begin{array}{c}\text { master } \\
\text { contactor } \\
\text { switch-on }\end{array}$} & total'+' & 120.12 & 1.86 & $\begin{array}{c}\mathrm{R}=52.2 \mathrm{k} \Omega \\
\mathrm{U}=280.9 .3 \mathrm{~V}\end{array}$ \\
\hline & total'-' & 0 & 123.56 & $\begin{array}{c}\mathrm{R}=51.4 \mathrm{k} \Omega \\
\mathrm{U}=0 \mathrm{~V}\end{array}$ \\
\hline & grouped & 57.72 & 63.74 & $\begin{array}{l}\mathrm{R}=52.6 \mathrm{k} \Omega \\
\mathrm{U}=130.8 \mathrm{~V}\end{array}$ \\
\hline \multirow{3}{*}{$\begin{array}{l}\text { no-load } \\
30 \mathrm{~km} / \mathrm{h}\end{array}$} & total'+' & idem & idem & - \\
\hline & total'-' & idem & idem & - \\
\hline & grouped & idem & idem & - \\
\hline
\end{tabular}

It is shown that determination of insulation weakness is independent of whether battery pack is connected or not or whether there is current in capacitive load or power circuit. This result provides experimental testification for online monitor of failure diagnosis and high voltage safety management system based on microprocessor. With determination method of single point insulation weakness proposed in this paper, insulation resistance can be measured accurately and location of it can be also detected.

To further study determination of multiple points insulation weakness, a high voltage DC hardware-in-loop was made. 2, 3 and 4 points insulation weakness were studied in detail. Experimental and analytical analyses were done to study the effect of number of testing circuit connected at the same time to measurement result. It also validates the determination method for multiple-points insulation weakness.

\subsection{Connection condition of main power circuit}

Monitor objectives of dynamic electrical parameters method include wiring connection point and battery pack. The electrochemical polarized internal resistance of the battery should be considered. At extreme conditions with temperature ranging from -20 to 35 Celsius degree, SOC varying within $10 \%$ and $100 \%$ and discharging rate varying from $\mathrm{C} / 3$ to $3 \mathrm{C}$, contact resistance is obtained with value varying from 200 to $600 \mathrm{mohm}$ at laboratory condition. In the case of battery breakdown or certain contact looses, the resistance will be far higher than this range.

To study the relation of electrical parameter and contact resistance, CAN data is collected every 0.2 second under different operating conditions. Fig. 5 shows measured current, contact resistance in a 30 minutes maximum vehicle speed test. Calculation base points were chosen to be $2.4 \mathrm{~A}$ and $118.9 \mathrm{~A}$. If we consider the condition that the resistance is lower than $600 \mathrm{mohm}$ as the whole power circuit not being changed, two calculated contact resistance of most operation points are within this range though some abnormal value may occur.

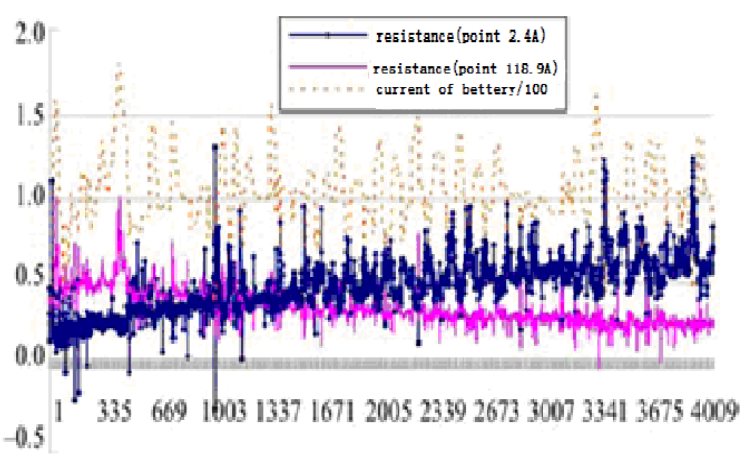

Figure 5:Calculation of contact resistance in 30min top speed test

For abnormal points of calculated contact resistance by on base point, we will check whether calculated contact resistance is within normal range by using another base point. Between point 4822 and 4871 , current varies from 8 to $10.2 \mathrm{~A}$, base point with small current $(2.4 \mathrm{~A})$ corresponds to a contact resistance ranging from 2.93 to $428 \mathrm{ohm}$, which is obviously abnormal compared to 400 mohm, however contact resistance calculated by large current base point is from 198 to $238 \mathrm{mohm}$ which is considered to be normal. The reason of it is that actual current is small when base point is chosen to be $2.4 \mathrm{~A}$, I1 is close to I2, the influence of the error of sensor to calculation is non-negligible, while a base point that has larger current than actual current, a correct analysis of contact resistance can be made. When actual current is 130.2 to $128.8 \mathrm{~A}$ which close to base point current of $118.9 \mathrm{~A}$, the effect of current sensor shift is magnified. As a result contact resistance cannot be accurately calculated. To validate the calculation method of dynamic electrical parameter further, abnormal points of contact resistance during the entire discharge process are summarized and analyzed, as shown in Tab. 2 .

The reasons for variance in contact resistance are listed below. Circuit modeling may not be complete, speed of data acquisition and synchronization are not satisfied, base point not adjusted according to real time parameter. What 
is more, the internal resistance of the battery is affected a lot by many conditions such as temperature, discharging current and SOC. In practice, if base point is dynamically adjusted, the influence of SOC and temperature may be eliminated.

Table2: Parameter comparison of "abnormity value" of contact resistance

\begin{tabular}{|c|c|c|c|l|}
\hline $\begin{array}{c}\text { abnormal } \\
\text { points }\end{array}$ & $\begin{array}{c}\text { bus } \\
\text { current/A }\end{array}$ & $\begin{array}{c}\text { contact resistance } \\
\text { calculated by } \\
\text { current base point } \\
\text { of } 2.4 \mathrm{~A} / \mathrm{m} \Omega\end{array}$ & $\begin{array}{c}\text { contact } \\
\text { resistance } \\
\text { calculated by } \\
\text { current base } \\
\text { point of } \\
118.9 \mathrm{~A} / \mathrm{m} \Omega\end{array}$ & \multicolumn{1}{|c|}{ analyse } \\
\hline $4949 \sim 4952$ & 120.3 & $348 \sim 357$ & $-4000 \sim-3330$ & $\begin{array}{l}\text { calculated normally } \\
\text { by current base point } \\
\text { of 2.4A }\end{array}$ \\
\hline $4953 \sim 4957$ & 112.9 & $362 \sim 380$ & $847 \sim 1695$ & $\begin{array}{l}\text { calculated normally } \\
\text { by current base point } \\
\text { of 2.4A }\end{array}$ \\
\hline $4958 \sim 4961$ & 120.3 & $383 \sim 393$ & $476 \sim 544$ & $\begin{array}{l}\text { calculated normally } \\
\text { by current base point } \\
\text { of 2.4A }\end{array}$ \\
\hline 4973 & 87.9 & 473 & -54.7 & $\begin{array}{l}\text { calculated normally } \\
\text { by current base point } \\
\text { of 2.4A }\end{array}$ \\
\hline 5010 & 83.3 & 418 & -84.5 & $\begin{array}{l}\text { calculated normally } \\
\text { by current base point } \\
\text { of } 2.4 \mathrm{~A}\end{array}$ \\
\hline 7791 & 118.5 & 508 & $\begin{array}{l}\text { calculated normally } \\
\text { by current base point } \\
\text { of 118.9A but } \\
\text { smaller(influenced by } \\
\text { SOC) }\end{array}$ \\
\hline $7027 \sim 7058$ & 113.1 & $433 \sim 451$ & $-175 \sim-520$ & $\begin{array}{l}\text { calculated normally } \\
\text { by current base point } \\
\text { of } 2.4 \mathrm{~A}\end{array}$ \\
\hline $645 \sim 6449$ & 17.2 & $2162 \sim 2297$ & $127 \sim 148$ & $\begin{array}{l}\text { calculated normally } \\
\text { by current base point } \\
\text { of } 2.4 \mathrm{~A}\end{array}$ \\
\hline
\end{tabular}

Table 3: Validation test result of contact point inspection

\begin{tabular}{|c|c|c|c|c|}
\hline $\begin{array}{c}\text { DC } \\
\text { supply }\end{array}$ & contactor & $\begin{array}{l}\text { bus } \\
\text { curre } \\
\text { nt/A }\end{array}$ & $\begin{array}{c}\text { voltage of } \\
\text { measure point } / \mathrm{V}\end{array}$ & result and analyse \\
\hline \multirow{4}{*}{$\begin{array}{l}\text { power } \\
\text { off }\end{array}$} & switch-off & - & -0.001 & \multirow{2}{*}{$\begin{array}{l}\text { The voltage is }-0.001 \mathrm{~V} \text {. } \\
\text { The circuit has null shift } \\
\text { and has been loop. }\end{array}$} \\
\hline & switch-on & - & +11.70 & \\
\hline & switch-off & - & -0.002 & \multirow{2}{*}{$\begin{array}{l}\text { The circuit has not been } \\
\text { part loop. The DC supply } \\
\text { discharge with constant } \\
\text { current. }\end{array}$} \\
\hline & switch-on & 0 & +11.63 & \\
\hline \multirow{5}{*}{$\begin{array}{l}\text { power } \\
\text { on }\end{array}$} & switch-on & 2.3 & +11.69 & \multirow{5}{*}{$\begin{array}{l}\text { The DC supply discharge } \\
\text { with constant current. } \\
\text { The change of bus } \\
\text { current does not cause } \\
\text { abnormal of contactor } \\
\text { diagnosis circuit. And } \\
\text { diagnosis circuit also has } \\
\text { not influence on power } \\
\text { system. }\end{array}$} \\
\hline & switch-on & 3 & +11.69 & \\
\hline & switch-on & 4 & +11.64 & \\
\hline & switch-on & 10 & $\begin{array}{r}+11.59 \\
\end{array}$ & \\
\hline & switch-on & 15 & +11.66 & \\
\hline
\end{tabular}


From the experiment data above, we can conclude that with dynamic parameter calculation method, if the base point current is not chosen to be too close to actual current, say there should be at least $10 \mathrm{~A}$ difference, contact resistance will be calculated in reasonable range.

\subsection{High voltage contact condition}

Since low voltage circuit is needed to monitor high voltage contact condition, something unpredictable may happen, thus experiment using simulated environment is conducted. A 64V lead acid battery is used and DC supply is used as load with auxiliary battery of $12 \mathrm{~V}, \mathrm{R} 0$ is 200kohm. Experiment result is shown in Tab. 3.

\section{Online monitor and diagnosis strategy}

\subsection{Power circuit diagnosis}

ECU with high speed, real-time and great data analysis function should be exploited to realize diagnosis strategy so that accurate and complete data of high voltage circuit can be recorded.

A dynamic current-voltage database is used in the NVM of high voltage management system, as shown in Tab. 4.

Five base point current that are least close to actual current are chosen to calculate resistance. If 4 of 5 calculated resistances is within the range of 200 to $600 \mathrm{mohm}$, then the connection is in normal condition and the average resistance is taken to be current resistance. If actual current is in the +/- 1A range of any current in Tab. 4, it can replace corresponding data. If calculated resistance is larger than 600 mohm or 2 times larger than previous insulation resistance, emergency program to monitor connection condition is turned on, if this condition happens three times in series, we can confirm a connection degradation. Calculated resistance will tell failure level such as power circuit connection bad, extreme bad or disconnected, then failure treatment process will be started.

Table 4: Data of dynamic I-U

\begin{tabular}{|c|c|c|c|c|c|c|}
\hline $\begin{array}{c}\text { Current/ } \\
\mathrm{A}\end{array}$ & 5 & 15 & 25 & 35 & $\ldots$ & 140 \\
\hline $\begin{array}{c}\text { Voltage/ } \\
\text { V }\end{array}$ & 304.8 & 301.4 & 299.2 & 297.8 & $\ldots$ & 276.8 \\
\hline $\begin{array}{c}\text { refresh } \\
\text { time }\end{array}$ & 17 & 1 & 2 & 1 & $\ldots$ & 3122 \\
\hline
\end{tabular}

\subsection{High voltage contact point diagnosis}

Fig. 4. shows the diagram of high voltage contact point diagnosis, it can be observed that what the diode in auxiliary circuit blocks is discharging current. When there is output power, it won't generate failure in either main or auxiliary circuit even if monitoring is on.
When motor is in powering mode or regenerating mode, the contact point must be closed, no diagnosis circuit is needed, contact point diagnosis should be conducted when there is no output power, which is at zero bus current. Diagnosis period doesn't need to be too short, $500 \mathrm{~ms}$ will be fine, synchronization and reliability can be approved during actual vehicle test.

\section{5 conclusion}

The mathematical model of diagnosis method for several critical condition is studied and validated with experiment. To satisfy the requirement of failure diagnosis and high voltage safety management based on microprocessor, online diagnosis strategy is studied and its effectiveness, response and reliability are validated in hardware-in-loop and actual vehicle test.

\section{Authors}

Professor level senior engineer, Zhao chunming China Automotive Technology And Research Center, Tel: 13920025865 Fax: 022-66320013-6615 Email:zhaochunming@catarc.ac.cn

assistant engineer, Li qing

Tianjin Qingyuan Electric Vehicle Co.Ltd

Tel: 15900343194 Fax: 022-66320013-6615

Email:lq@qyev.com 